\title{
Gossypiboma- A Rare Case of Spontaneous Intraluminal Migration of Surgical Sponge
}

\author{
Authors \\ Dr Govind Madhav (MBBS, DNB)*, Dr Siddhartha Rao (MBBS, MS, Senior Consultant), \\ Dr Md Muzamil (MBBS, DNB), Dr Amit Kumar Rai (MBBS, DNB, FMAS) \\ Department of General Surgery, Jaipur Golden Hospital, Sector-3, Rohini, New Delhi, India \\ *Corresponding Author \\ Dr Govind Madhav
}

\begin{abstract}
Gossypiboma or textiloma is a mass of cotton matrix which is retained in body cavity following a surgical procedure. Most frequently diagnosed in abdominal cavity following emergency surgeries especially Gynecological and Obstetric procedure.

Clinical manifestations of these cases are as fistula, abscess, intestinal obstruction or aseptic fibrotic reaction, which develops into mass abdomen. But intraluminal migration of retained surgical sponge in gastro-intestinal lumen is rare.

We are reporting a rare case of spontaneous migration of surgical sponge into lumen of Ileum in a 34 years old lady following Caesarean section 8 months ago. Clinical examination revealed a palpable lump in left Para umbilical region. CT scan of abdomen revealed mass in small intestine (Ileum).

On exploratory laparotomy a mass was seen in Ileum with minimal surrounding adhesion. Mass was excised in toto followed by Ileo-ileal anastomosis.

A $30 X 30 \mathrm{~cm}$ surgical sponge was removed from Ileal loop.
\end{abstract}

Keywords: Gossypiboma, Intraluminal migration, Retained surgical sponge, Ileocecal valve.

\section{Case Report}

A 34 years lady came with complaint of lump on the left side of umbilicus, which she noticed for last 3 months, associated with mild to moderate pain in lower abdomen, no postural or diurnal variation of pain. She has lost around $13 \mathrm{kgs}$ of weight in past 2 months. She also complained of multiple episodes of vomiting with loss of appetite.

Her general examinations and laboratory parameters were within normal limits. On abdominal examination, a palpable mass was present on the left side of umbilical region extending to the hypogastrium and left lumbar region which was firm to hard in consistency, smooth surface and mobile in all directions. She had no tenderness, guarding, rigidity or organomegaly. A surgical Pfannensteil scar mark was seen with sluggish bowel sound on auscultation. She has a history of caesarean section 8 month back. CECT scan of abdomen showed - a mass in ileum with wall edema. She was planned for exploratory laparotomy under general anesthesia.

Intra-operatively a mass was seen in ileum with surrounding minimal adhesion and edema. It was an ileal mass. There was adhesion on antimesenteric border of ileum which on examination revealed small rent on anti-mesenteric border. Intestinal clamps were applied on both ends of mass with clear margins, the rent was opened and a $30 \times 30 \mathrm{~cm}$ surgical mop was found in the lumen. 


\section{JMSCR Vol||08||Issue||07||Page 476-479||July}

The segment of ileum was excised in toto. Anastomosis was done between two ends of ileum. The abdomen was closed with all precautions and counts of sponges and instruments confirmed. Postoperative period was uneventful and the patient recovered well. After 8 days, patient was discharged and advised for follow-up.

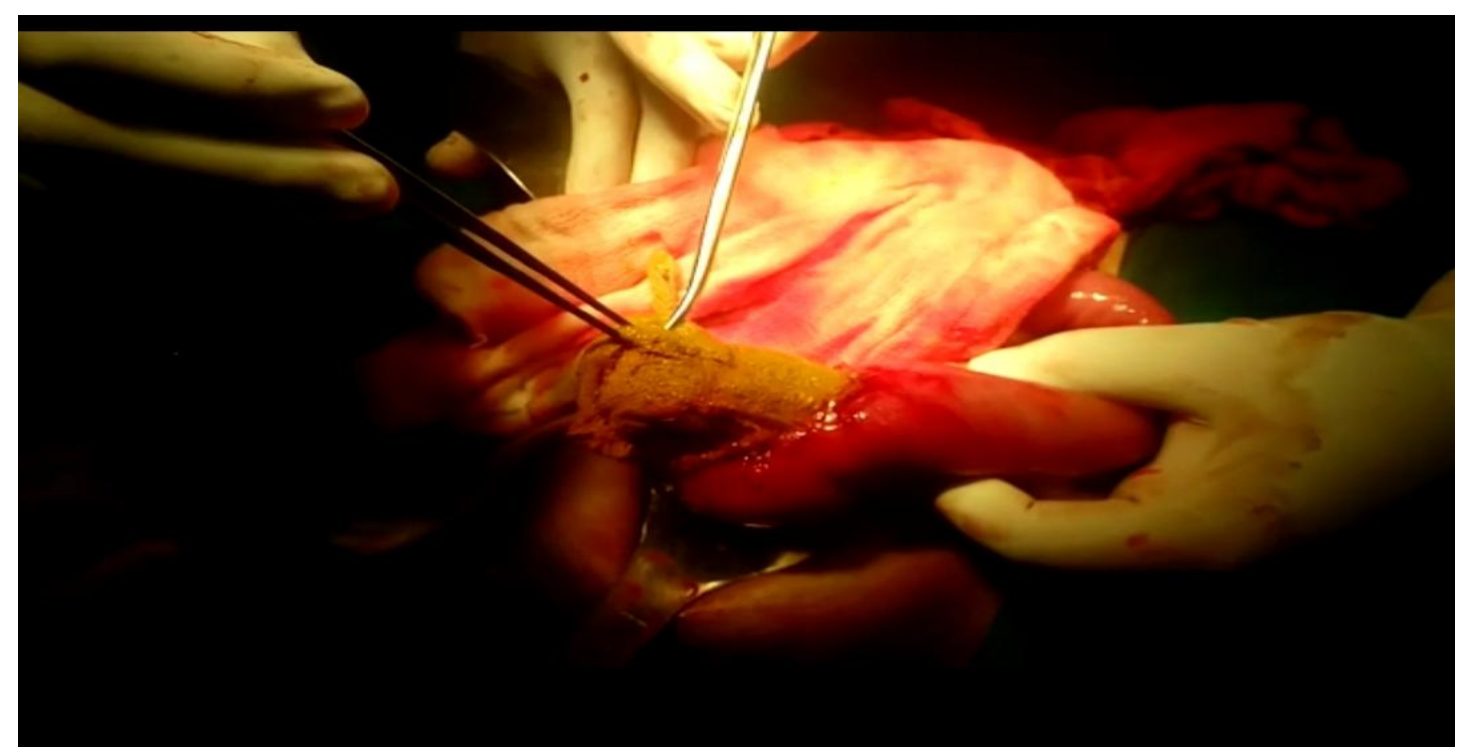

Figure 1: Intraoperative photo

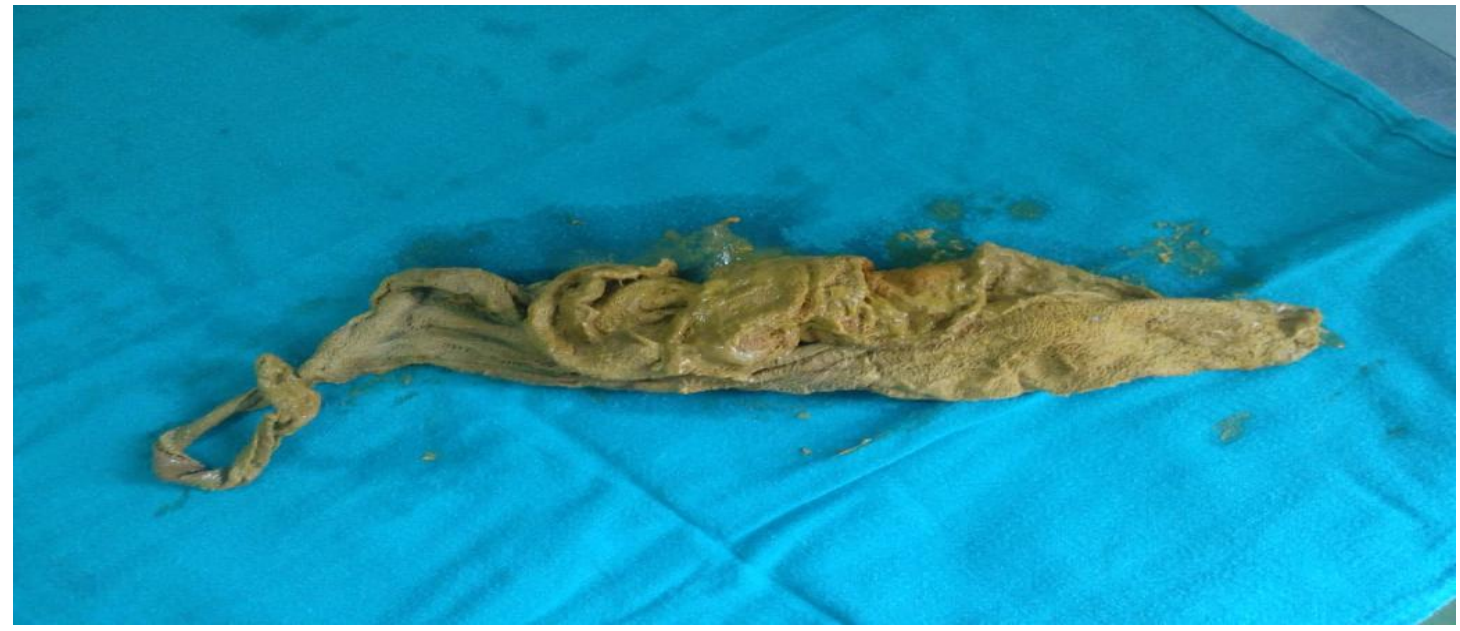

Figure 2: Extracted surgical sponge

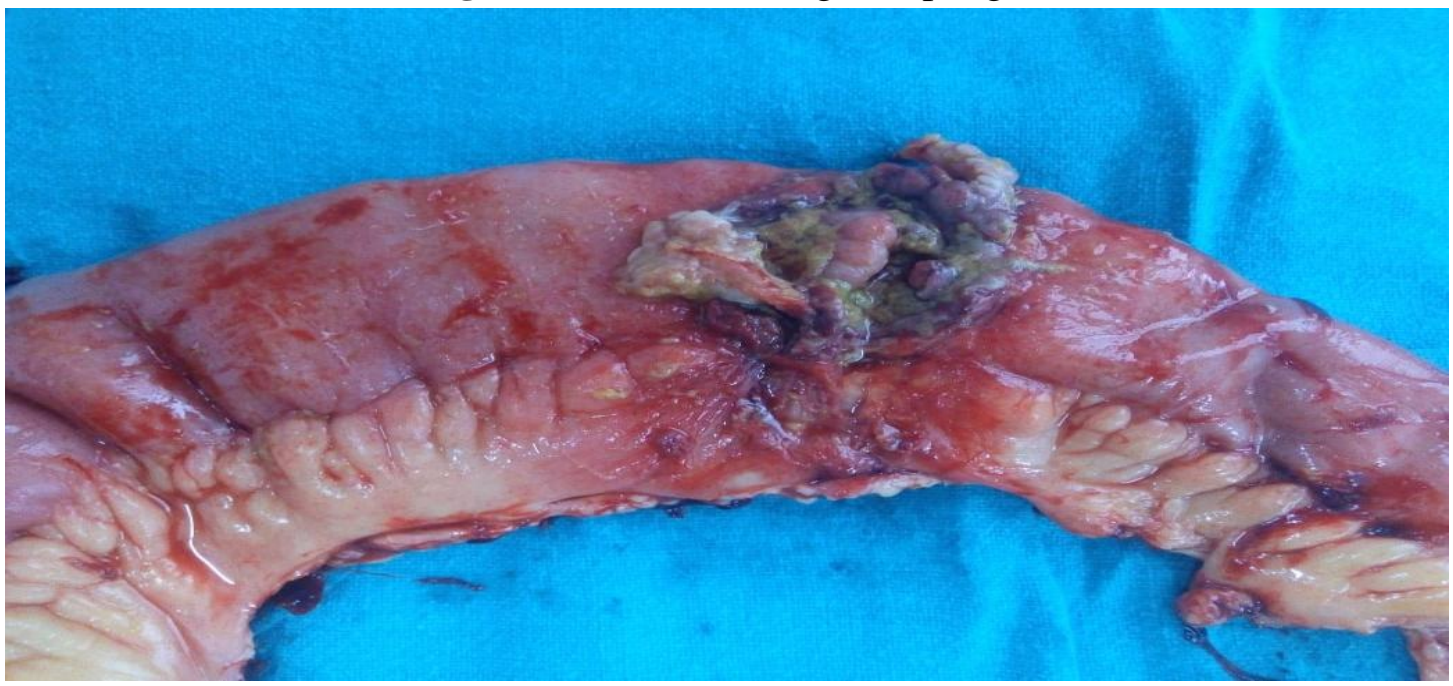

Figure 3: Resected segment of Ileum 


\section{Discussion}

Following intra-abdominal surgeries incidence of retained instruments or sponge ranges from $1: 1000$ to $1: 1500$, but it is more commonly found then reported ${ }^{[1]}$. Fear of litigation, disclosing the error by other clinician or asymptomatic gossypiboma may mask the real incidence. But possibility of it can be kept as differential $\operatorname{diagnosis}^{[2]}$.

Regarding transmural migrations, a hypothesis based on animal study proposed four stages, foreign body reaction, secondary infection, mass formation and remodeling. Peristaltic activity advanced the mop usually to stay in the terminal ileum, resulting in obstruction ${ }^{[3]}$. After migration of the mop into the lumen, the wall of the intestine closes completely ${ }^{[4]}$. A rent on the antimesentric border of the ileum was identified in our case which could be the fistulous tract leading to intraluminal migration of the surgical sponge.

A retained surgical sponge can penetrate the intestine, urinary bladder, thorax or vagina. Intestinal penetration may occur in any part of the intestinal tract. The small intestine is the most affected site due to its thin wall and large outer surface.

Diagnosis of these cases are difficult as radiological feature are variable, CECT scan is the investigation of choice ${ }^{[5]}$. It may show complex mass with variable density, calcification, spongiform gas and radiopaque marker. In our patient since the sponge lacked a radiopaque marker it was not visible on radiological investigations. Detection by plain X-ray is difficult, especially when surgical sponges have not been provided with the radiopaque marker or when the marker has been fragmented or disintegrated $^{[6]}$. USG may be helpful and may show an echogenic, complex hypoechoic area, or cystic mass with acoustic shadow or may be normal $^{[7]}$. MRI can also use for diagnosis. After confirmation gossypibomas requires removal, as it is related to complications and morbidities ${ }^{[6-7]}$. This usually necessitates laparotomy. However, alternative methods like laparoscopy, percutaneous extraction (with or without the help of interventional radiology) and endoscopic procedures have been reported. Spontaneous extrusion is an extremely rare favorable outcome [7].

Factors which lead to gossypiboma could be high body mass index, emergency surgery, difficult operative procedures, surgeon's fatigability, poor tracking of sponges, nursing and surgical team change during surgery, poor light conditions. Few cases have been reported in spite of normal sponge count at the end of surgery ${ }^{[6-7]}$. To prevent intra-operative loss of sponges, it can be held on forceps ${ }^{[8]}$. New techniques like Electronic article surveillance system, Bar code or Radiofrequency identification system, these help in tracing sponges during and after surgery.

\section{Conclusion}

Gossypiboma is an avoidable accident if we follow meticulous record keeping in Operative theatre. Surgical team should develop the habit of performing a through routine post procedure wound body cavity exploration before closure of abdominal cavity and should use radiopaque makers on sponges.

Inspite of modern technology cases of gossypiboma exists in modern medicine. As litigations are becoming common, for this problem prevention is the best treatment.

\section{References}

1. Sozutek A, Yormaz S, Kupeli H, Saban B. Transgastric migration of gossypiboma remedied with endoscopic removal: a case report. BMC research notes. 2013 Dec;6(1):413.

2. Kadam A, Jain S, Salve L. Gossypiboma: A Rare Case of Spontaneous Intraluminal Migration of Surgical Sponge.

3. Silva CS, Caetano MR, Silva EA, Falco L, Murta EF. Complete migration of retained surgical sponge into ileum without sign of open intestinal wall. Archives of 
gynecology and obstetrics. 2001 May 1;265(2):103-4.

4. Düx M, Ganten M, Lubienski A, Grenacher L. Retained surgical sponge with migration into the duodenum and persistent duodenal fistula. European radiology. 2002 Dec 1;12(3):S74-7.

5. Haddad R, Judice LF, Chibante A, Ferraz D. Migration of surgical sponge retained at mediastinoscopy into the trachea. Interactive cardiovascular and thoracic surgery. 2004 Dec 1;3(4):637-40.

6. Sarda AK, Pandey D, Neogi S, Dhir U. Postoperative complications due to a retained surgical sponge. Singapore medical journal. 2007 Jun;48(6):e160-4.

7. Zantvoord $Y$, van der Weiden RM, van Hooff MH. Transmural migration of retained surgical sponges: a systematic review. Obstetrical \& gynecological survey. 2008 Jul 1;63(7):465-71.

8. Glockemann K, Fröhlich H, Bernhards J, Büttner D. Peranal passage of a surgical sponge: fortunate outcome of an intraoperative oversight. Der Chirurg; Zeitschrift fur alleGebiete der operative Medizen. 2005 Jun;76(6):595-8. 